\title{
TECNOLOGIAS PARA O DESENVOLVIMENTO INCLUSIVO: COPRODUÇÃO DE TECNOLOGIAS PARA CEGOS COM BASE NA INTERAÇÃO SOCIAL
}

Marilise Luiza Martins dos Reis Sayão Universidade Federal de Santa Catarina mariliselmreis@gmail.com

\section{Resumo}

O projeto "Tecnologias para o desenvolvimento inclusivo: coprodução de tecnologias para cegos com base na interação social" objetiva desenvolver com os alunos e professores das engenharias e licenciaturas do campus UFSC/Blumenau, uma proposta de intervenção para o desenvolvimento de tecnologias para cegos pautada na interação sociotécnica. Alunos, professores, associados e profissionais da Associação de Cegos do Vale do Itajaí, desenvolvem atividades e estratégias que resultem em tecnologias desenvolvidas em coprodução. Como primeiros resultados a serem compartilhados, temos a coprodução de uma vestimenta para o coral e para o time de golbol, aulas de informática e a repaginação conjunta do brechó da instituição.

Palavras-chave: Coprodução. Tecnologias. Inclusão. Cegos.

\section{TECHNOLOGIES FOR INCLUSIVE DEVELOPMENT: COPRODUCTION OF TECHNOLOGIES FOR BLINDNESS BASED ON SOCIAL INTERACTION}

\begin{abstract}
The project "Technologies for inclusive development: coproduction of technologies for the blind based on social interaction" aims to develop a proposal for intervention with the students and professors of the engineering and undergraduate courses of the campus UFSC / Blumenau, to develop technologies for the blind based on socio-technical interaction. Students, teachers, associates and professionals of the "Associação de Cegos do Vale do Itajaí", develop activities and strategies that result in technologies developed in coproduction. As the first results to be shared, we are coproducing a dress for the choir and goboal team, computer classes and the joint repagination of the institution's brechery.
\end{abstract}

Keywords: Coproduction. Technologies. Inclusion. Blind.

\section{TECNOLOGÍAS PARA EL DESARROLLO INCLUSIVO: COPRODUCCIÓN DE TECNOLOGÍAS PARA CEGOS CON BASE EN LA INTERACCIÓN SOCIAL}

\section{Resumen}

El proyecto "Tecnologías para el desarrollo inclusivo: coproducción de tecnologías para ciegos con base en la interacción social" objetiva desarrollar con los alumnos y profesores de las ingenierías y licenciaturas del campus UFSC/Blumenau, una propuesta de intervención para el desarrollo de tecnologías para ciegos pautada en la. la interacción sociotécnica. Alumnos, profesores, asociados y profesionales de la "Associação de Cegos do Vale do Itajaî", desarrollan actividades y estrategias que resulten en tecnologías desarrolladas en coproducción. Como primeros resultados a ser compartidos, tenemos la coproducción de una vestimenta para el coral y golbol, clases de informatica y la repaginación conjunta del brechó de la institución.

Palavras clave: Coproducción. Tecnologías. Inclusión. Ciego. 
Tecnologias para o desenvolvimento inclusivo: coprodução de tecnologias para cegos com base na interação social

\section{INTRODUÇÃO}

O projeto de extensão “Tecnologias para o Desenvolvimento Inclusivo: coprodução tecnologias assistivas para cegos com base na interação social" objetiva desenvolver com os alunos, professores dos cursos da UFSC, campus de Blumenau, e com a Associação de Cegos do Vale do Itajaí (ACEVALI), uma proposta de intervenção para o desenvolvimento de tecnologias para cegos, e pessoas com baixa visão, pautada por uma abordagem de interação sociotécnica.

A Acevali está localizada no município de Blumenau. Foi fundada em 28 de fevereiro de 1987 e seu foco de ação é a alfabetização da pessoa deficiente visual através do sistema Braille, bem como o repasse de noções de orientações e mobilidade.

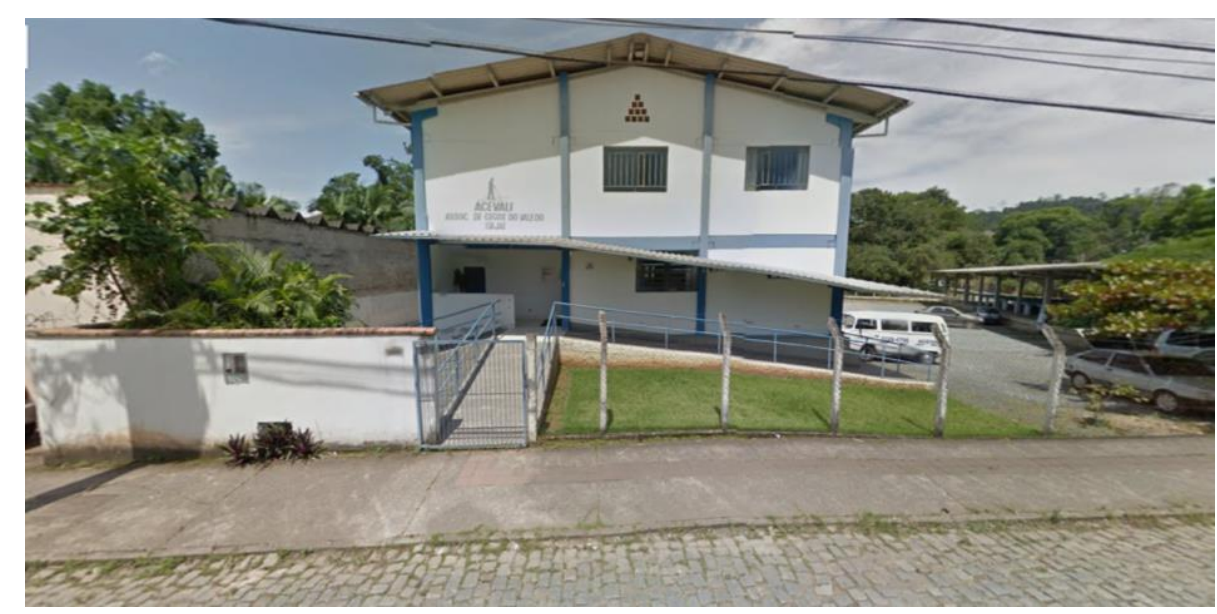

Figura 1. Vista parcial do prédio da Associação de Cegos do Vale do Itajaí (ACEVALI) (Fonte: arquivo do projeto de extensão)

Busca assegurar aos seus associados continuidade e descobertas de habilidades e potencialidades, oferecendo serviços de atendimento educacional especializado, aulas de informática no sistema Dos Vox e Jaws, atividades esportivas, artesanato, musicalização, acompanhamento psicológico, passeios, festas comemorativas, atendimento e acompanhamento sócio assistencial. É uma entidade sem fins lucrativos, e carente, que atende associados dentro de suas necessidades, inserindo-os como cidadãos de direitos na comunidade e motivando-os a superar suas limitações de visão e a lutar contra o preconceito e desconhecimento da sua condição.

A temática "tecnologias assistivas" foi eleita como objeto de intervenção levando em conta este contexto, tendo em vista a amplitude que seu processo de produção gera e o envolvimento que os futuros profissionais (engenheiros de controle e automação, têxtil e de materiais e licenciados em matemática e química) poderão ter com a comunidade na qual a 
Tecnologias para o desenvolvimento inclusivo: coprodução de tecnologias para cegos com base na interação social

universidade está inserida. Cabe pontuar que a Tecnologia Assistiva é um termo ainda novo, utilizado para identificar todo o arsenal de recursos e serviços que contribuem para proporcionar ou ampliar habilidades funcionais de pessoas com deficiência e, consequentemente, promover vida independente e inclusão (BERSCH, 2013).

É também definida como "uma área do conhecimento, de característica interdisciplinar, que engloba produtos, recursos, metodologias, estratégias, práticas e serviços que objetivam promover a funcionalidade, relacionada à atividade e participação de pessoas com deficiência, incapacidades ou mobilidade reduzida, visando sua autonomia, independência, qualidade de vida e inclusão social" CATÁlOGO NACIONAL DE PRODUTOS DE TECNOLOGIA ASSISTIVA, 2018).

São inúmeras as tecnologias assistivas que encontramos, voltadas a proporcionar ou ampliar essas habilidades funcionais de pessoas com deficiência. Mas também é muito grande a falta de participação das pessoas que farão uso efetivo desses recursos ou serviços na definição dos problemas e construção das soluções, ou seja, na sua coprodução. Rafael Giglio Bueno, em sua dissertação de mestrado "Tecnologia Assistiva como política pública: inclusão na agenda de pesquisa e coprodução com o usuário" (1990) defendeu a maior participação do usuário no desenvolvimento de tecnologias voltadas para pessoas com deficiência. Bueno acredita que as iniciativas seriam muito mais válidas e eficientes quando a pessoa, que fará uso do produto, atue em conjunto com pesquisadores e desenvolvedores.

Um caso marcante dos problemas gerados pela falta de participação dos potenciais usuários na coprodução desses artefatos aconteceu em 2014 quando alguns estilistas da Casa de Criadores, evento de desfiles de São Paulo, decidiram desenvolver o que chamaram de "moda para deficientes visuais", partindo do pressuposto de que os cegos precisariam usar texturas distintas, bolsos com detalhes em relevo, elásticos ao invés de botões e tecidos diferentes para distinguir os lados das roupas. De acordo com o Movimento Cidade para Todos, essa é uma visão equivocada, uma vez que menospreza a intelectualidade e a capacidade dos cegos de vestirem-se, certamente porque, mais uma vez, não foram consultados nesse projeto.

Infelizmente esta não é uma exceção. Muitos dos projetos em engenharia desenvolvidos por nossos alunos, ainda que tenham vocação forte para a inovação social, para a inclusão, para a cidadania, carecem de interação com os potencias usuários. Quando questionados quanto ao grau de interação desenvolvido com os sujeitos alvo, a resposta quase sempre é nenhuma. Os projetos são desenvolvidos, e ressalte-se que com as melhores das intenções, com pouca ou nenhuma interação. Pesquisadores reservados em seus laboratórios, imersos na busca de soluções para os 
Tecnologias para o desenvolvimento inclusivo: coprodução de tecnologias para cegos com base na interação social

problemas e para o desenvolvimento de tecnologias com pouca prática interativa. Estas práticas precisam ser incentivadas, e é este o intuito do referido projeto.

Objetivamos fazer com que os futuros profissionais formados pela universidade desenvolvam a prática da coprodução de seus artefatos tecnológicos, pautados por uma abordagem de interação sociotécnica que envolva o maior número de agentes possíveis, levando em consideração: a) a articulação entre os diferentes atores nesse processo como as empresas, a comunidade de cegos e todos que os cercam, a universidade, a gestão pública, a cidade em geral; b) a participação efetiva desses sujeitos quanto às tecnologias a serem produzidas, deixando de serem apenas receptores finais; c) elaboração de tecnologias que atendam as especificidades desses sujeitos na relação com a cidade em que vivem e com as diferentes atividades que os alunos desempenham; d) atendimento das normas técnicas e das legislações pertinentes; e) questões ambientais, de acessibilidade e de sustentabilidade.

É possível melhorar a vida dessas pessoas, mas para isso é preciso aprender a ouvi-los, a dialogar com eles, a construir soluções coletivamente. É esse exercício que os acadêmicos fizeram nesse projeto, contribuindo para a formação do futuro profissional como um sujeito capaz de oferecer soluções e de avaliar o impacto das intervenções sociotécnicas. Nesse sentido, esse artigo objetiva apresentar alguns resultados dessa intervenção, discorrendo sobre algumas das ações já iniciadas: reativação das aulas de informática, reelaboração da vestimenta do coral e do time de golbol, e repaginação do brechó.

\section{METODOLOGIA E INSERÇÃO EM CAMPO}

A inserção no campo de intervenção se deu por meio de duas metodologias: a pesquisaação e a metodologia de desenvolvimento de projetos centrado no usuário. No que se refere a pesquisa-ação, é o método de pesquisa que agrega diversas técnicas de pesquisa social com as quais se estabelece uma estrutura coletiva, participativa e ativa no nível da captação da informação (MOURA e BARBOSA, 2006; THIOLLENT, 2011). Cabe destacar a importância que tem a participação das pessoas envolvidas no problema. Já da metodologia de desenvolvimento de projetos centrados no usuário, que pressupõe que haja o maior número de interações possíveis entre projetistas e usuários, destacamos sua importância quando se trata do caso de produtos assistivos, já que os usuários apresentam requisitos particulares e específicos, muitas vezes difíceis de serem entendidos e capturados por projetistas que não compartilhem as mesmas necessidades (CHELLA, 2014). 
Tecnologias para o desenvolvimento inclusivo: coprodução de tecnologias para cegos com base na interação social

Por meio das entrevistas realizadas pelas bolsistas do projeto, e pelos alunos da disciplina de Introdução ao Design de Moda, identificamos, juntamente com os associados, as suas principais necessidades para então por em andamento as ações indicadas. Essa Associação conta com 40 associados frequentes, com faixa etária entre 40 e 80 anos, que se dedicam a atividades físicas, - há uma pequena academia na instituição - além de um time de golbol. Há um atleta na modalidade atletismo. Há aulas de artesanato na qual participam 20 associados. Há um coral com 15 membros associados, e uma banda de música chamada Coça Coça.

Sobre o coral nos foi pontuado pelos associados o desejo de desenvolvimento de uma vestimenta própria para a atividade, pois eles só tinham uma camiseta bem simples. Além disso, há um brechó na instituição considerado bastante importante, pois é dele que sai o maior rendimento para a associação. Ainda havia a aula de informática que era muito importante para a inserção cidadã dessas pessoas, mas há mais de um ano estavam sem voluntários para ministrarem essas aulas. Outra atividade bastante pontuada foi referente aos uniformes dos times de golbol, masculino e feminino, bastante competitivo e participante de diversas competições anualmente. Com esses primeiros resultados de intervenção interativa, demos início as seguintes ações:

Reativação das aulas de informática: a acadêmica do curso de Engenharia Têxtil e bolsista do programa de extensão PROBOLSAS - UFSC, Larissa Satomi Costa iniciou, no mês de maio, as aulas de informática na associação, tanto ensinando, enquanto aprendendo a dominar o sistema Dos Vox e Jaws. As aulas aconteceram durante todo o ano de 2017, às segundas-feiras, das 9 hs às $10 \mathrm{hs}$ e das 10:45h às 11:45h, na sala de informática da ACEVALI, com pelo menos 5 alunos por turma. 
Tecnologias para o desenvolvimento inclusivo: coprodução de tecnologias para cegos com base na interação social

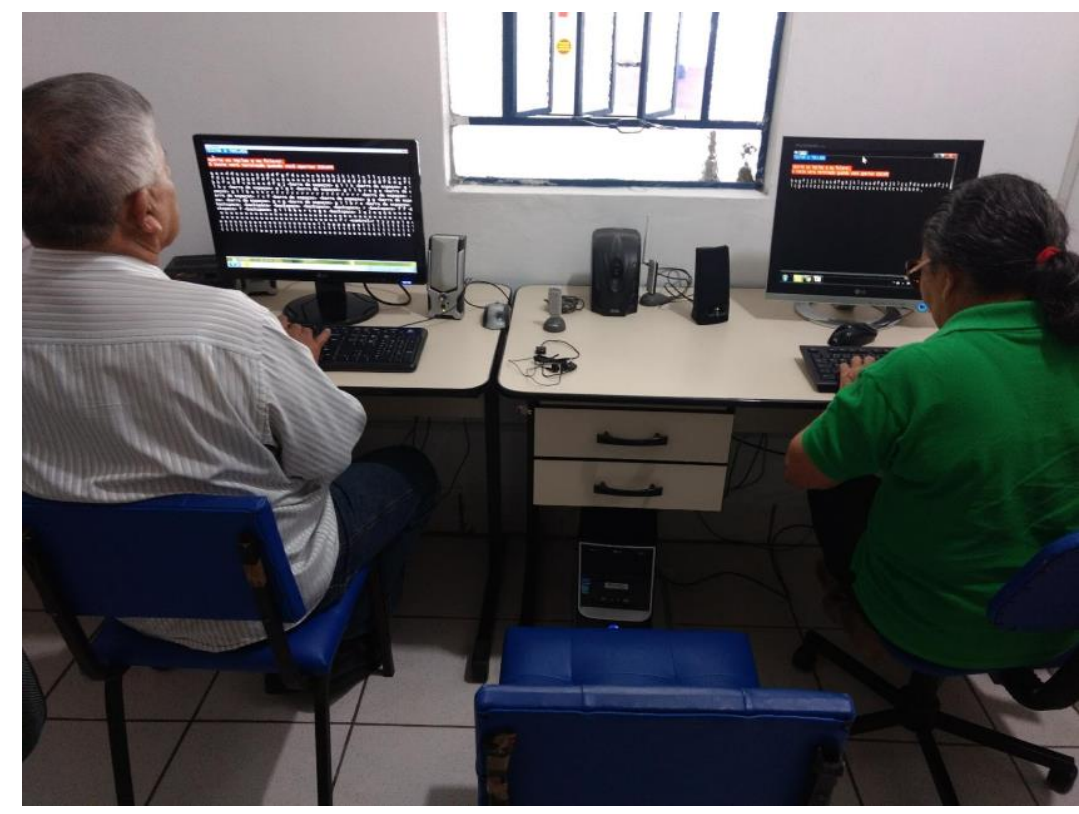

Figura 2. Associados da Acevali em aula de informática ministrada pela bolsista Larissa Satomi da Costa (Fonte: arquivo do projeto de extensão)

Reformulação do uniforme do coral: $\mathrm{O}$ objetivo dessa ação foi trabalhar de forma integrada com os associados da ACEVALI, tentando contemplar todas as demandas observadas para a criação do uniforme. Desta forma, a parceria com os profissionais e associados da instituição envolvida no projeto foi fundamental para que se criasse um sistema de trabalho relacional, de coprodução e cocriação. Partindo desse princípio, criou-se um conjunto de ações que foram desenvolvidas na disciplina Introdução ao Design de Moda, do curso de Engenharia Têxtil, durante o ano de 2017, e com as bolsistas Larissa Satomi Costa e Laura Palermo Gomes, ambas estudantes de Engenharia Têxtil, as quais permitiram a relação entre as atividades e os conhecimentos construídos ao longo do semestre.

Ao longo do desenvolvimento da presente ação, buscou-se criar produtos com valor agregado diferenciado, utilizando os princípios do Desenho Universal e da cocriação, capazes de atender à funcionalidade, aliar conforto à estética, provocar um olhar mais sensível e tentar entender o público-alvo, seu dia a dia, seu corpo, suas necessidades, seus desejos. Os alunos desenharam a coleção e, após estudos, fundamentação teórica e análise da vida e obra de um artista brasileiro, escolheram os modelos para serem confeccionados. Nessa perspectiva, o projeto teve como tema-inspiração a obra "Bailarina", do artista visual Antônio da Silva (2016). 
Tecnologias para o desenvolvimento inclusivo: coprodução de tecnologias para cegos com base na interação social

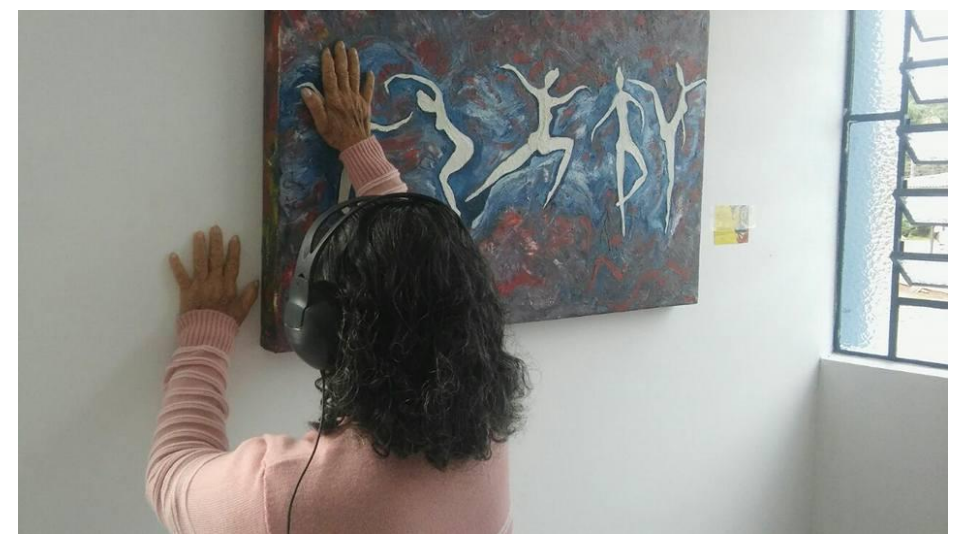

Figura 3. Associada da ACEVALI participando da exposição da obra Bailarina apreciando a obra com as mãos e ouvindo a música que expressa as cores da obra, tendo em vista que a obra foi criada para deficientes visuais.

(Fonte: arquivo do projeto de extensão)

Os tecidos foram escolhidos considerando os desejos dos associados, participantes do coral. Eles queriam que seus uniformes fossem prioritariamente na cor azul (cor da logo da instituição) e fossem confeccionados com tecidos que não amassassem e nem sujassem com facilidade e que fossem fáceis de vestir. O projeto e as peças foram apresentados aos sujeitos da pesquisa, e eles selecionaram, dentre todos, dois modelos de uniformes: um no formato de beca e outro no formato de poncho. O primeiro possuía mangas e lembrava o modelo de becas, utilizadas em apresentações de corais e formaturas. O segundo apresentava uma modelagem mais ampla e única, sem mangas, lembrando a forma de um poncho. Algumas alterações foram feitas até a apresentação do projeto final. Os modelos foram adaptados seguindo as orientações dadas pelos associados: uniforme azul (cor da logo da instituição), modelagem simples, ampla, que facilitasse o vestir e que ficasse bem em diferentes corpos, ser unissex, comprimento da beca deveria ser até o joelho, abertura somente nas laterais. As logomarcas das instituições foram bordadas e, transcritas em braile com aviamentos em relevo. 
Tecnologias para o desenvolvimento inclusivo: coprodução de tecnologias para cegos com base na interação social

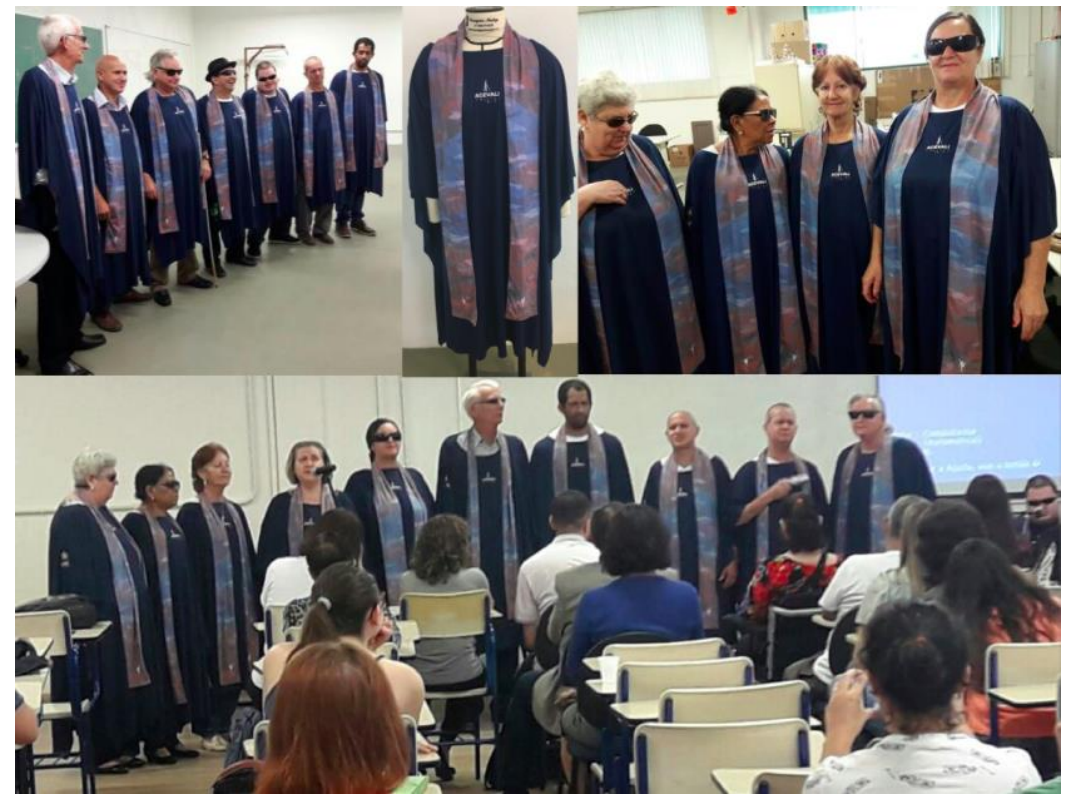

Figura 4. Detalhes dos uniformes e apresentação do coral Vozes do Coração da Acevali, 2017 (Fonte: arquivo do projeto de extensão).

Reelaboração do uniforme de Golbol: O objetivo dessa ação está sendo a de atender um grupo de deficientes visuais participantes do time de Golbol (masculino e feminino), quanto ao seu uniforme, de modo que ele venha a atender com mais eficiência o desempenho dos atletas praticantes desse esporte. Assim, trabalhando diretamente com os atletas, um grupo de alunos criou um conjunto de ações que foram desenvolvidas na disciplina Introdução ao Design de Moda, do curso de Engenharia Têxtil, durante o ano de 2017, as quais permitiram a relação entre as atividades e os conhecimentos construídos ao longo do semestre. Em interação com estes atletas os alunos coletaram dados em campo, a partir de observação participante e entrevistas, e identificaram as principais demandas do grupo que foram listadas, em síntese, como as seguintes: ausência de conforto térmico e ergonômico e a baixa qualidade do uniforme como um todo. Desses dados, tomaram como objetivo propor modelos de uniformes que levassem a melhorias no desempenho dos atletas, a partir de modificações e adaptações. Por fim, desenvolveram uma coleção que atendesse às questões indicadas pelos atletas. Além disso, tomaram como inspiração o artista plástico carioca Marcelo Cunha, que pinta quadros com a boca e os pés. Escolheram a obra "O pescador" e dela exprimiram a cartela de cores. Todo o desenvolvimento da coleção levou em conta todas as normas técnicas do esporte.

O projeto deteve-se apenas na idealização das peças, desenho técnico e fichas técnicas, por ora. 
Tecnologias para o desenvolvimento inclusivo: coprodução de tecnologias para cegos com base na interação social

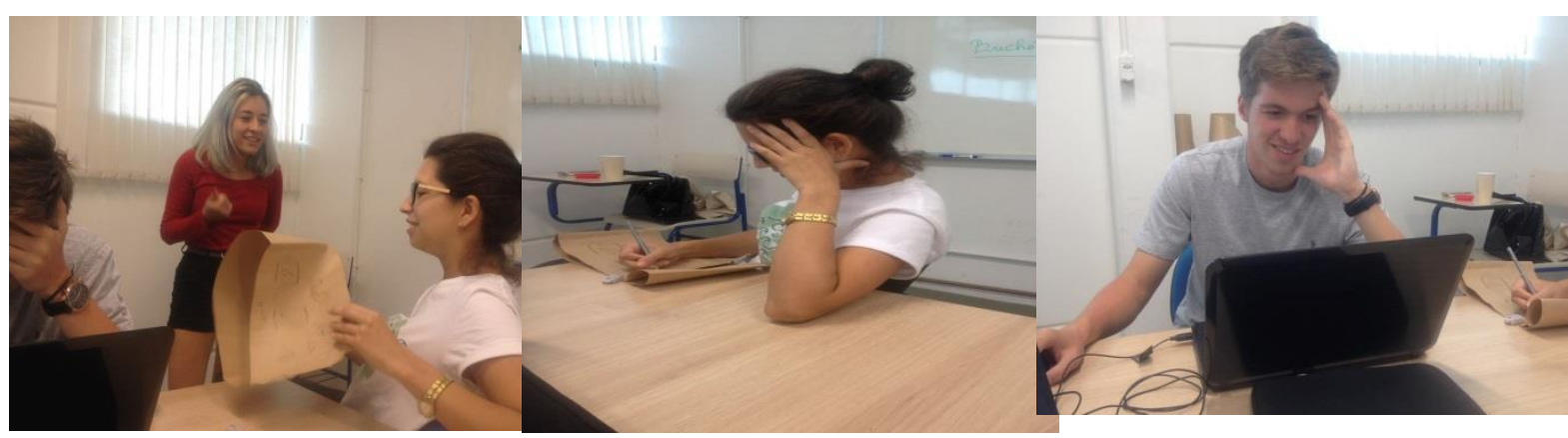

Figura 5. Estudantes de Engenharia Têxtil desenvolvendo os modelos, desenhos e fichas técnicas para o novo uniforme do Golbol.

(Fonte: Arquivo da disciplina Introdução ao Design de Moda)

Reconfiguração do brechó: O objetivo dessa ação foi a de melhorar as instalações do brechó com vistas a aumentar os lucros da associação, bem como a de melhorar as condições de acessibilidade para as pessoas com deficiência, já que a grande maioria dos associados compra as suas vestimentas no brechó, dada as dificuldades que enfrentam para comprarem roupas e calçados no comércio convencional. Partindo desse princípio, criou-se igualmente um conjunto de ações que foram desenvolvidas na disciplina Introdução ao Design de Moda, do curso de Engenharia Têxtil, durante o ano de 2017, as quais permitiram a relação entre as atividades e os conhecimentos construídos ao longo do semestre. Dois grupos de alunos avaliaram, conjuntamente com os associados, as condições estruturais do brechó, bem como as condições das roupas existentes e de acessibilidade da pessoa com deficiência, para então dar início às seguintes ações: Campanha em rede sociais e na UFSC de doação de novas peças. Customização de peças. Organização completa do brechó por categorias e considerando as questões de acessibilidade da pessoa com deficiência. Reconfiguração do ambiente do brechó. Divulgação em redes sociais das melhores peças disponíveis para aumentar a procura e as vendas.

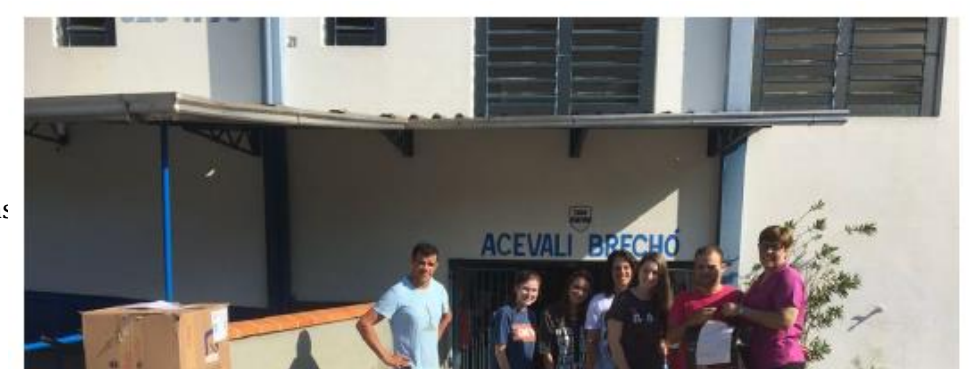


Tecnologias para o desenvolvimento inclusivo: coprodução de tecnologias para cegos com base na interação social

Figura 6. Alunos do curso de Engenharia Têxtil entregam doações e peças customizadas ao brechó da ACEVALI.

(Fonte: Arquivo da disciplina de Introdução ao Design de Moda)

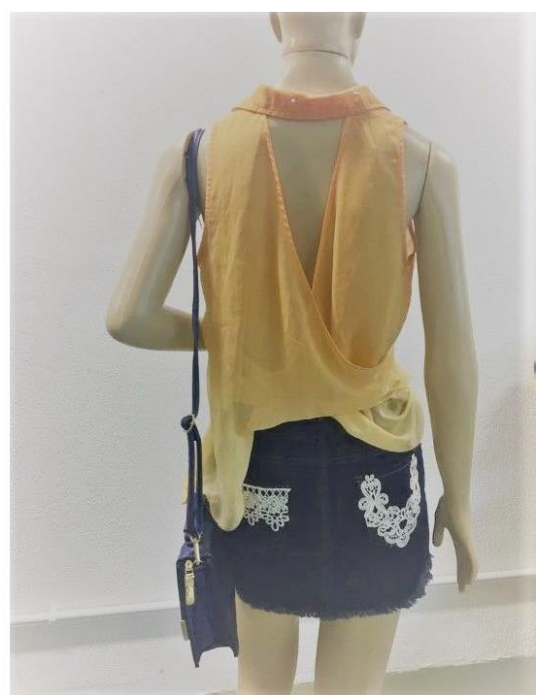

Figura 7. Uma das peças customizadas pelos alunos do curso de Engenharia Têxtil que foram entregues ao brechó da ACEVALI.

(Fonte: Arquivo da disciplina de Introdução ao Design de Moda) 
Tecnologias para o desenvolvimento inclusivo: coprodução de tecnologias para cegos com base na interação social

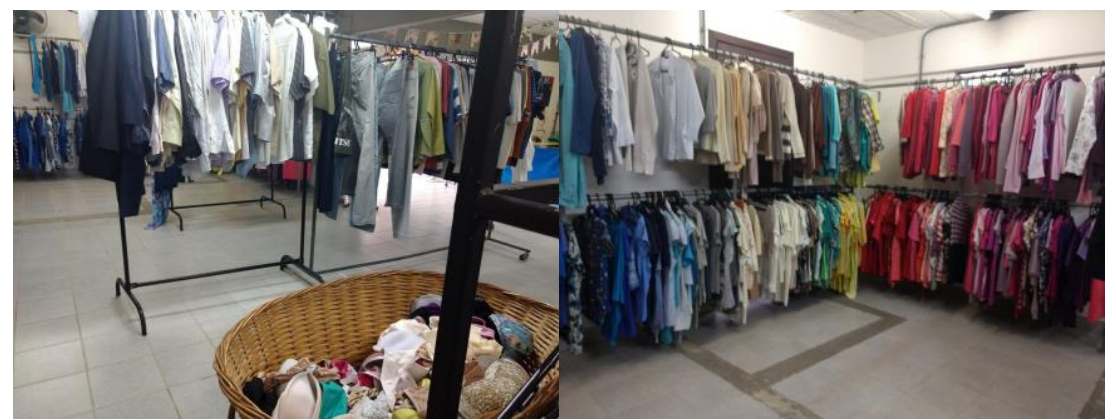

Figura 8. Imagens da reconfiguração do brechó com base na acessibilidade, mobilidade e autonomia para as pessoas cegas.

Destacamos que o trabalho realizado pelos alunos, bolsistas, professores e associados, não foi apenas o de reorganizar espaços e peças de roupas, mas também de criar uma coleção para o brechó em conjunto com os associados. Desse modo, dois grupos desenvolveram peças customizadas tomando como inspiração obras de artistas brasileiros, e a noção de assistividade, criando assim diferencial nessas peças.

\section{RESULTADOS E ANÁLISES}

Tivemos e ainda teremos várias ações a serem empreendidas nesse projeto, que se estenderá por todo ano de 2018. Felizmente fomos contemplados pelo edital PROBOLSAS 2017/2018 com duas bolsas, o que fortaleceu a continuidade das ações com a ACEVALI. Entre os resultados, consideramos que foram, em sua maioria, mais positivos do que negativos. Primeiro, foi possível reativarmos as aulas de informática da Associação, contemplando mais de 10 associados, que se encontram inseridos no mundo digital, aprendendo a dominar e utilizar o sistema Dos Vox e Jaws. Novos uniformes para o Coral foram desenvolvidos, graças à parceria com a empresa "Imperial Assessoria Empresarial Ltda", a qual aceitou patrocinar e confeccionar os uniformes do coral da ACEVALI, conforme o modelo escolhido pelos associados. Foram produzidas trinta peças, em diferentes tamanhos, para melhor atender as diferentes estaturas dos associados, o que superou as nossas expectativas.

No dia 16 de setembro, o coral da ACEVALI se apresentou pela primeira vez com os novos uniformes no evento "Setembro Branco da Inclusão 2017: ações afirmativas para a inclusão da pessoa com deficiência", atividade promovida pela Prefeitura de Blumenau, por meio da Secretaria de Desenvolvimento Social (SEMUDES) e Rede de Inclusão, organizada pelo SENAC, SESI e UFSC. Após essa estreia, o coral já se apresentou inúmeras vezes e, com uma vestimenta apresentável, como eles mesmo relatam, tem se destacado na região, inclusive podendo aumentar o dinheiro em caixa da associação, ao cobrarem cachê. 
Tecnologias para o desenvolvimento inclusivo: coprodução de tecnologias para cegos com base na interação social

Com a reformulação das peças do uniforme de Golbol, temos agora uma coleção masculina e feminina para serem confeccionadas. A fase atual é a de busca de parcerias com empresas têxteis da região. A ideia é conseguirmos aprimorar e confeccionar a coleção até o final do ano, empreendendo ajustes ainda necessários junto aos atletas. Tivemos sucesso com a primeira etapa da reconfiguração do brechó. Todas as peças customizadas foram vendidas e aumentou a frequência de consumidores no espaço devido ao gerenciamento de uma conta no Instagram. A ideia para este ano é dar continuidade a reconfiguração do brechó, coletando e customizando mais peças, assim como dar continuidade as melhorias do ambiente em termos de acessibilidade e visibilidade em redes sociais, com maior inclusão dos associados na tarefa.

Um ponto a ser melhorado ainda é uma maior articulação com os princípios da tecnologia assistiva, tendo em vista que os princípios da coprodução já estão bem melhor consolidados.

\section{CONSIDERAÇÕES FINAIS}

Pontuamos inicialmente que estava entre os objetivos desse projeto desenvolver com os alunos, professores dos cursos da UFSC, campus de Blumenau, e com a Associação de Cegos do Vale do Itajaí (ACEVALI), uma proposta de intervenção para o desenvolvimento de tecnologias para cegos, e pessoas com baixa visão, que se pautasse por uma abordagem de interação sociotécnica. Tudo isto com vistas a ampliar a visão dos futuros acadêmicos formados nesse campus quanto aos impactos que o desenvolvimento de tecnologias poderá gerar com e para a comunidade na qual a universidade está inserida.

Ao destacarmos algumas das ações desenvolvidas ao longo desse artigo, a retomada das aulas de informática, o desenvolvimento dos uniformes do coral da Associação e do Golbol e a reconfiguração do brechó, vimos se consolidar o trabalho colaborativo na construção de tecnologias para cegos e pessoas com baixa visão; o voluntariado de nossos alunos, além do alcance de outras questões como: articulação entre os diferentes atores nesse processo, como as empresas, a comunidade de cegos e todos que os cercam, a universidade, a gestão pública, a cidade em geral; b) a participação efetiva desses sujeitos quanto às tecnologias a serem produzidas, deixando de serem apenas receptores finais; c) elaboração de tecnologias que atendam as especificidades desses sujeitos na relação com a cidade em que vivem e com as diferentes atividades que os alunos desempenham; d) atendimento das normas técnicas e das legislações pertinentes; e) o respeito às questões ambientais, de sustentabilidade e de acessibilidade. 
Tecnologias para o desenvolvimento inclusivo: coprodução de tecnologias para cegos com base na interação social

Um dos elementos que precisamos fortalecer ainda para que todas essas ações cheguem aos seus objetivos finais é o aumento da rede de parcerias, que chamamos de rede sociotécnica e da ideia de coprodução e assistividade. Uma coisa é produzir tecnologias para alguém, outra é produzir para e com alguém. Este é o grande desafio do projeto que se coloca para professores, associados e estudantes: entender as deficiências não como limitadoras, mas como aquelas que potencializam a criação das tecnologias mais amplas, sociais, inclusivas e universais. Como o projeto prossegue durante o ano de 2018, é essa nossa principal tarefa para que todos os objetivos aos quais nos propusemos sejam alcançados.

\section{REFERÊNCIAS}

BERSCH, Rita. Introdução à tecnologia assistiva. Tecnologia e Educação, RS: Porto Alegre, 2013.

BUENO, Rafael Giglio. Tecnologia Assistiva como política pública: inclusão na agenda de pesquisa e coprodução com o usuário. Tese de Doutorado. Universidade Estadual de Campinas, UNICAMP, 2016. Disponível em: http://repositorio.unicamp.br/handle/REPOSIP/321437.

CATÁlOGO NACIONAL DE PRODUTOS DE TECNOLOGIA ASSISTIVA. Disponível em: < http://assistiva.mct.gov.br/>. Acesso em: 01 de fevereiro de 2018.

CHELLA, Marco Tulio et. all. Modelos e abordagens de projeto para o desenvolvimento de tecnologias assistivas. Revista Gestão \& Conexões. Vitória (ES), v. 3, n. 1, jan./jun. 2014.

MOURA, D. G e BARBOSA, E. F. Trabalhando com Projetos: Planejamento e Gestão de Projetos Educacionais. Rio de Janeiro: Ed. Vozes, 2006.

THIOLLENT, M. J. M. Metodologia de Pesquisa-Ação. 18. ed. São Paulo: Cortez, 2011. 